\title{
Acurácia, precisão e robustez das estimativas da digestibilidade aparente da matéria seca determinada com o uso de indicadores em ovinos
}

\author{
Paulo Henrique Mazza Rodrigues ${ }^{1,2}$, Rodrigo da Costa Gomes ${ }^{3}$, Renata Farinelli de \\ Siqueira ${ }^{1}$, Paula Marques Meyer ${ }^{4}$, Renato Ranzini Rodrigues ${ }^{1}$
}

\footnotetext{
${ }^{1}$ Departamento de Nutrição e Produção Animal, FMVZ/USP, Av. Duque de Caxias Norte, 225, CEP: 13635-900, Pirassununga, SP.

2 Bolsista Produtividade Pesquisa CNPq.

3 Departamento de Zootecnia, FZEA/USP, Av. Duque de Caxias Norte, 225, CEP: 13635-900, Pirassununga, SP.

4 Instituto Brasileiro de Geografia e Estatística (IBGE), Rua Duque de Caxias, 1332, $2^{\circ}$ andar/salas 1 e 3, Centro, CEP: 13630-095, Pirassununga, SP.
}

RESUMO - O objetivo foi avaliar a acurácia, precisão e robustez das estimativas da digestibilidade aparente da matéria seca obtidas utilizando-se como indicadores fibra em detergente ácido indigestível (FDAi), fibra em detergente neutro (FDNi) indigestível, lignina em detergente ácido (LDA), LDA indigestível (LDAi) e óxido crômico em comparação ao método de coleta total de fezes. Dezoito ovinos (56,5 \pm 4,6 kg PV) foram designados aleatoriamente a dietas compostas de 25, 50 ou 75\% de concentrado e feno de Coast cross por 25 dias. As fezes foram coletadas por cinco dias para determinação da digestibilidade aparente da MS. As amostras de alimentos e fezes foram incubadas no rúmen de três bovinos por 144 horas, para obtenção das frações indigestíveis. Óxido crômico foi administrado a 4,0 g/animal/dia. A acurácia foi avaliada pela comparação do viés médio (DAMS predito - DAMS observado) entre os indicadores; a precisão, por meio da raiz quadrada do erro de predição e do erro residual; e a robustez, pelo estudo da regressão entre o viés e o consumo de matéria seca, o nível de concentrado e o peso vivo. A recuperação fecal e a acurácia das estimativas da digestibilidade aparente da MS foram maiores para FDAi, seguida pela FDNi, LDAi, pelo óxido crômico e depois pela lignina em detergente ácido. O viés linear foi significativo apenas para FDAi, FDNi e LDAi. O uso de óxido crômico permitiu estimativas mais precisas da digestibilidade aparente da MS. Todos os indicadores foram robustos quanto à variação no consumo de matéria seca e apenas LDAi e óxido crômico foram robustos quanto aos níveis de concentrado na dieta. O óxido crômico não foi robusto quando houve variação no peso vivo animal. Assim, a FDAi é o indicador mais recomendado na estimativa da digestibilidade aparente da MS em ovinos quando o objetivo é comparar aos dados da literatura, enquanto o óxido crômico é mais recomendado quando o objetivo é comparar tratamentos dentro de um mesmo experimento.

Palavras-chave: fibra, lignina, recuperação fecal, viés

\section{Accuracy, precision and robustness of in vivo dry matter digestibility estimates by different markers in ovine}

\begin{abstract}
This study aimed at evaluating the accuracy, precision and robustness of in vivo dry matter apparent digestibility estimates (DMAD), using as markers indigestible acid detergent fiber, indigestible neutral detergent fiber, acid detergent lignin, indigestible acid detergent lignin and chromic oxide in comparison to the fecal total collection. Eighteen wethers (56.5 $\pm 4.6 \mathrm{~kg} \mathrm{BW}$ ) were randomly assigned to diets containing 25, 50 or $75 \%$ of concentrate and Coast cross hay for 25 days. Feces were collected during the five days to determine apparent digestibility of dry matter and samples of feed and feces were incubated for 144 hours in bovine rumen to obtain the indigestible fractions. Chromic oxide (4.0 g/animal) was offered daily. Accuracy was evaluated by comparing mean bias of estimates (predicted dry matter apparent digestibility - observed dry matter apparent digestibility) among markers. Precision was assessed by the root mean square prediction error and the residual error; robustness was studied by the regression between bias and dry matter intake, diet concentrate level and animal body weight. Fecal recovery and accuracy of dry matter apparent digestibility estimates were higher for indigestible acid detergent fiber, followed by indigestible neutral detergent fiber, indigestible acid detergent lignin and chromic oxide, and at last for acid detergent lignin. Linear bias was significant only for indigestible acid detergent fiber, indigestible neutral detergent fiber and indigestible acid detergent lignin. By using chromic oxide it was possible to estimate dry matter apparent digestibility more precisely. All markers were robust regarding to variation of dry matter intake while only indigestible acid detergent lignin and chromic oxide were robust regarding to concentrate levels in the diet. Chromic oxide was not robust when animal body weight varied. In this experimental condition, indigestible acid detergent fiber is the most recommended marker to estimate dry matter apparent digestibility in ovine when the objective is to compare the results with the ones found in literature. On the other hand, chromic oxide is the most recommended marker when the objective is to compare treatments within the same experiment.
\end{abstract}

Key Words: bias, fecal recovery, fiber, lignin 


\section{Introdução}

O uso de indicadores permite a estimativa da digestibilidade aparente da matéria seca da dieta e de suas frações para animais de maneira menos laboriosa que a coleta total de fezes, o que justifica o interesse científico por este método indireto. Entretanto, os resultados encontrados são muito variáveis, provavelmente em decorrência da diversidade das dietas, dos animais e das metodologias utilizados.

Grande parte das investigações com indicadores da produção fecal resume-se à comparação das estimativas de digestibilidade àquelas observadas pela coleta total de fezes, o que permite a avaliação da acurácia das estimativas, mas não de sua precisão. Neste caso, os coeficientes de digestibilidade obtidos pela coleta total de fezes representam o valor real para aquela resposta e devem ser utilizados como base para o estudo do erro residual, também chamado viés, das estimativas obtidas com os indicadores, sendo que a avaliação de acurácia e precisão são fundamentadas neste parâmetro. Além disso, são raros os estudos que incluíram uma avaliação da robustez dos indicadores na estimativa da digestibilidade da matéria seca da dieta diante da variação de outros fatores associados às condições experimentais, sejam eles ligados aos animais (como o peso vivo), à dieta (como digestibilidade e relação volumoso:concentrado), ou a ambos (como o consumo de MS).

Assim, os objetivos neste estudo foram determinar em ovinos a acurácia e precisão das estimativas da digestibilidade da matéria seca (DAMS), obtidas pelo uso da FDAi, FDNi, LDA, LDAi e do óxido crômico como indicadores da produção fecal, e avaliar a robustez desses indicadores em relação à variação no consumo de matéria seca considerando o nível de concentrado na dieta e o peso vivo animal.

\section{Material e Métodos}

O experimento foi realizado nas instalações do Laboratório de Nutrição de Ruminantes da Faculdade de Medicina Veterinária e Zootecnia da Universidade de São Paulo, Campus de Pirassununga, São Paulo.

Foram utilizados 18 ovinos deslanados adultos, machos mestiços da raça Santa Inês, com peso vivo médio de $56,5 \pm 4,6 \mathrm{~kg}$ ao início do experimento, mantidos em gaiolas de metabolismo providas de cocho e bebedouro individuais. Os animais foram aleatoriamente designados a uma das três dietas, contendo 25,50 ou $75 \%$ de concentrado, com base na matéria seca (Tabela 1). A composição química das dietas foi determinada segundo metodologia descrita pela AOAC (1980) para avaliação dos teores de matéria seca (MS), proteína bruta (PB), matéria mineral (MM), extrato etéreo (EE), cálcio (Ca) e fósforo (P). As frações FDN e FDA foram determinadas segundo Van Soest et al. (1991) e as concentrações de proteína degradável e nãodegradável no rúmen, bem como os nutrientes digestíveis totais (NDT), foram estimadas utilizando-se os valores preconizados pelo NRC (1989).

As dietas foram formuladas para ser isonitrogenadas e a ração foi fornecida em duas refeições, às 8 e 16 h, na forma de mistura completa. O experimento teve duração total de 25 dias, de modo que os primeiros 14 dias foram destinados à adaptação dos animais às dietas. Entre o 15으 e o 17 음 dia, foi avaliado o consumo de MS e os dados foram utilizados para estabelecer a restrição alimentar em $80 \%$ do consumo à vontade, realizado entre o $18^{\circ}$ e o $25^{\circ}$ dia. Entre o $21^{\circ}$ e e $25^{\circ}$ dia, foi realizada a coleta total de fezes para avaliação da digestibilidade in vivo.

Amostras da dieta (feno e misturas concentradas) foram coletadas diariamente durante os últimos 5 dias (21으 ao 25음ia), formando uma amostra composta. Para avaliação da digestibilidade por coleta total, as coletas de fezes, obtidas em bolsas coletoras, foram realizadas uma vez ao dia, às $8 \mathrm{~h}$. Depois que foram pesadas, uma amostra de $10 \%$ foi coletada para formação de uma amostra composta por animal. Posteriormente, foi processada em estufa de ar forçado a $65^{\circ} \mathrm{C}$, por 72 horas.

Tabela 1 - Composição das rações utilizadas no experimento, com base na matéria seca

\begin{tabular}{|c|c|c|c|}
\hline \multirow{2}{*}{$\begin{array}{l}\text { Item } \\
\text { Composição percentual }\end{array}$} & \multicolumn{3}{|c|}{ Concentrado (\%) } \\
\hline & 25 & 50 & 75 \\
\hline Feno de coast-cross & 75,0 & 50,0 & 25,0 \\
\hline Milho grão, moído & 21,6 & 44,7 & 67,7 \\
\hline Farelo de soja & 1,90 & 3,80 & 5,80 \\
\hline Sal branco & 0,50 & 0,50 & 0,50 \\
\hline Mistura mineral $^{1}$ & 1,00 & 1,00 & 1,00 \\
\hline \multicolumn{4}{|l|}{ Composição nutricional } \\
\hline Matéria seca (\%) & 91,10 & 90,70 & 90,30 \\
\hline Proteína bruta (\%) & 12,78 & 13,07 & 13,35 \\
\hline Proteína não-degradável $(\% \text { da } \mathrm{PB})^{2}$ & 33,57 & 37,20 & 40,68 \\
\hline Proteína degradável $(\% \text { da } \mathrm{PB})^{2}$ & 66,43 & 62,80 & 59,32 \\
\hline Fibra em detergente ácido (\%) & 28,46 & 20,90 & 13,35 \\
\hline Fibra em detergente neutro (\%) & 58,57 & 45,37 & 32,16 \\
\hline Fibra em detergente neutro efetiva $(\%)^{2}$ & 55,18 & 38,37 & 21,55 \\
\hline Extrato etéreo (\%) & 1,77 & 2,39 & 3,01 \\
\hline Matéria mineral (\%) & 8,01 & 6,09 & 4,17 \\
\hline Carboidratos não-fibrosos (\%) & 17,87 & 32,08 & 46,30 \\
\hline Nutrientes digestíveis totais $(\%)^{2}$ & 57,17 & 65,59 & 74,02 \\
\hline Cálcio (\%) & 0,55 & 0,49 & 0,42 \\
\hline Fósforo (\%) & 0,34 & 0,35 & 0,36 \\
\hline
\end{tabular}

${ }^{1}$ Composição por kg de mistura mineral: Ca - 180 g; P - 90 g; Mg - 20 g; S 20 g; Na - 100 g; Zn - 3.000 mg; Cu - 1.000 mg; Mn - 1.250 mg; Fe - 2.000 mg; Co 200 mg; I - 90 mg; Se - 36 mg; F (máximo) - 900 mg.

2 Estimado segundo o NRC (1989). 
Para avaliação da digestibilidade pela técnica do indicador externo segundo Bateman (1970), o óxido crômico foi administrado na dose de $4,0 \mathrm{~g}$ do indicador por animal/ dia, via oral e fornecido duas vezes ao dia (2,0 g por vez), no momento das refeições, por meio de cápsulas de gelatina (1,0 g por cápsula) e aplicador oral para ovinos. A avaliação da digestibilidade por esse indicador foi realizada em duas fases, entre o $16^{0}$ e $25^{\circ}$ dia, com uma fase de administração do marcador (entre $16^{\circ}$ e $20^{\circ}$ dia) e outra de administração do marcador e coleta de fezes (entre $21^{0}$ e $25^{\circ}$ dia), com duração de cinco dias cada uma, assegurando desta forma excreção homogênea do óxido crômico. A concentração de óxido crômico foi determinada por colorimetria por meio de sua reação com a s-difenilcarbazida, segundo Graner (1972).

Na avaliação com o uso dos indicadores internos fibra em detergente ácido indigestível (FDAi), fibra em detergente neutro indigestível (FDNi) e lignina indigestível (LDAi), amostras de alimentos e fezes foram incubadas em sacos de náilon, colocados no rúmen de três bovinos canulados, por 144 horas (Owens \& Hanson, 1992). Para uso, utilizaram-se três vacas mestiças não-lactantes e nãogestantes, canuladas no rúmen, com $650 \mathrm{~kg}$ de peso vivo médio. As vacas foram alimentadas com pastagem de Brachiaria brizantha à vontade e 2,0 kg de mistura concentrada composta de grãos de milho moído, farelo de soja e sal mineral. Para incubação, utilizaram-se sacos confeccionadas em tecido de náilon com porosidade de 50 micras, medindo $10,0 \times 20,0 \mathrm{~cm}$, que receberam, separadamente, aproximadamente 6 gramas de alimentos ou fezes secos em estufa de circulação de ar forçado a $65^{\circ} \mathrm{C}$ por 72 horas, previamente moídos em peneira de $5 \mathrm{~mm}$. Após o período de incubação, os sacos eram imediatamente lavados em água corrente e colocados em estufa a $65^{\circ} \mathrm{C}$ por 72 horas para posteriormente serem pesados e submetidos às análises bromatológicas.

O resíduo da incubação foi pressuposto indigestível e teve as concentrações de fibra em detergente ácido, fibra em detergente neutro e lignina em detergente ácido (LDA) determinadas segundo metodologias descritas por Van Soest et al. (1991). Adicionalmente, foi avaliada a lignina em detergente ácido presente na dieta total (não incubada no rúmen por 144 horas) como indicador interno. Para isso, as concentrações desta fração na ração total e nas fezes foram determinadas como descrito anteriormente.

Os cálculos dos coeficientes de digestibilidade aparente da matéria seca obtidos pelo método de coleta total ou pela técnica de indicadores foram realizados de acordo com o proposto por Church (1988).

O uso dos indicadores para a estimativa da digestibilidade aparente da matéria seca foi avaliado quanto à acurácia, à precisão e à robustez. A acurácia dos indicadores foi avaliada pelo viés médio, que é a diferença entre o valor predito pelo indicador e o valor observado pela coleta total de fezes. Portanto, o indicador mais acurado é aquele que possui um viés médio mais próximo de zero (Kohn et al., 1998). O cálculo do viés médio foi realizado segundo a fórmula abaixo:

$$
\text { Viés médio }=\frac{\sum(\text { predito }- \text { observado })}{n^{\circ} \text { observações }}
$$

A precisão é uma medida de dispersão entre os valores preditos e observados, ou seja, é a variabilidade média da distância entre o valor predito e o observado ou ainda, a variabilidade dos vieses (Kohn et al., 1998), que pode ser avaliada pela raiz quadrada média do erro de predição (RQMEP), cuja fórmula é apresentada a seguir:

$$
\text { RQMEP }=\sqrt{\frac{\sum(\text { predito }- \text { observado })^{2}}{n^{\circ} \text { observações }}}
$$

Entretanto, toda vez que o viés médio for alto (falta de acurácia), ocorre superestimativa da falta de precisão, ou seja, super-estimativa da raiz quadrada média do erro de predição, uma vez que a distância média entre o valor predito e o observado leva também ao aumento da variabilidade entre o predito e o observado. Portanto, a precisão é mais bem avaliada quando a raiz quadrada média do erro de predição é corrigida para falta de acurácia, gerando assim o erro residual, que é definido como o erro restante no modelo de predição, excluindo-se o erro devido ao viés médio (Kohn et al., 1998). O erro residual é também referido como o erro de predição, excluindo-se o viés médio, e obtido pela fórmula:

$$
\text { Erro residual }=\sqrt{\left[R Q M E P^{2}-(\text { viés_médio })^{2}\right]}
$$

Antes das comparações estatísticas propriamente ditas, os dados foram testados para normalidade dos resíduos (teste de Shapiro-Wilk) e homogeneidade de variâncias (teste de Hartley), segundo Ott (1983). Para se comparar a recuperação fecal e a acurácia das estimativas de digestibilidade aparente da matéria seca entre os indicadores, os dados de recuperação e vieses foram submetidos à análise de variância (PROC GLM do SAS) e as médias comparadas pelo teste Tukey (Sampaio, 1998). O teste t para média igual a zero (PROC UNIVARIATE do SAS) foi utilizado para avaliar a significância dos viéses médios. O nível de significância utilizado foi o de $5 \%$. 
Para se comparar a precisão entre os indicadores, os valores do erro residual foram submetidos ao teste de homogeneidade de variâncias (teste Hartley), segundo Ott (1983), e comparados dois a dois, utilizando-se o PROC TTEST (SAS, 1998).

A fim de se avaliar o comportamento do erro de predição dos marcadores (vieses) em função da variação dos valores observados de digestibilidade aparente da matéria seca, foi estimada a regressão entre os vieses e a digestibilidade aparente da matéria seca observada (coleta total de fezes), obtendo-se, desta forma, o viés linear (coeficiente angular), o coeficiente de determinação do modelo $\left(\mathrm{R}^{2}\right)$ e a significância do viés para cada indicador, pelo procedimento REG do SAS (SAS, 1998), segundo Kohn et al. (1998).

Por sua vez, a avaliação da robustez de cada indicador foi obtida regredindo-se o viés em função das variáveis selecionadas (consumo de matéria seca, nível de concentrado na dieta e peso vivo médio), realizada também pelo procedimento REG do SAS (SAS, 1998). A comparação entre os coeficientes angulares das retas foi realizada pela metodologia de comparação de retas, cujo princípio é testar a interação entre a variável selecionada e os indicadores, por meio da análise de variância (teste F) pelo PROC GLM (SAS, 1998), com os indicadores comparados dois a dois (Meyer et al., 2006a, b).

\section{Resultados e Discussão}

Todos os indicadores (Tabela 2) apresentaram recuperação fecal inferior a 100\% ( $\mathrm{P}<0,05)$. A FDAi apresentou a maior recuperação e a LDA a menor e as médias não diferiram $(\mathrm{P}>0,05)$ entre FDNi, LDAi e óxido crômico.

A recuperação incompleta dos indicadores, observada neste experimento levou a estimativas enviesadas da digestibilidade aparente da MS (Tabela 3). Todos os indicadores subestimaram as estimativas de digestibilidade aparente da MS, fato comprovado pelos vieses médios negativos e estatisticamente diferentes de zero. Entretanto, os valores de vieses médios diferiram entre si $(\mathrm{P}<0,05)$, sugerindo a possibilidade do emprego de um indicador mais acurado para a estimativa da produção fecal e, enfim, da digestibilidade aparente da MS em ovinos.

Menor erro de predição da digestibilidade aparente da matéria seca foi obtido pelo uso da fibra em detergente ácido indigestível, seguido por aquele obtido com a fibra em detergente neutro, a lignina indigestível, o óxido crômico e, enfim, pela lignina. Isto indica que as estimativas obtidas com o uso da fibra em detergente ácido indigestível foram as mais acuradas, ou seja, as que mais se aproximaram do valor real da digestibilidade aparente da matéria seca, observada pela coleta total de fezes. Ao contrário, a lignina estimou valores de digestibilidade aparente da matéria seca com menor acurácia, ou seja, com dados mais distantes dos valores reais. A acurácia das estimativas obtidas com os indicadores avaliados está condizente com suas medidas de recuperação fecal (Tabela 2). Recuperações menores indicam que a concentração do indicador nas fezes também é menor, o que pode levar a uma superestimativa da excreção das frações dietéticas de interesse e, logo, valores de digestibilidade subestimados.

Assim como neste estudo, em trabalhos anteriores, com a fibra em detergente ácido indigestível como indicador em ruminantes, constam estimativas enviesadas da digestibilidade aparente da matéria seca e recuperações fecais diferentes de 100\% (Piaggio et al., 1991; Barros et al., 2007; Zeoula et al., 2002; Oliveira Jr. et al., 2004). Todavia, em trabalho com eqüinos, Oliveira et al. (2003) observaram que a fibra em detergente ácido indigestível proporcionou estimativas da digestibilidade aparente da matéria seca iguais à observada pela coleta total de fezes, resultado de recuperações fecais deste indicador estatisticamente iguais a $100 \%$ (recuperação real igual a 98,8\%).

Tabela 2 - Recuperação fecal obtida com indicadores para estimativa da digestibilidade aparente da matéria seca em ovinos

\begin{tabular}{|c|c|c|c|c|c|}
\hline \multirow{2}{*}{$\begin{array}{l}\text { Item } \\
\text { Recuperação fecal }\end{array}$} & \multicolumn{5}{|c|}{ Indicador } \\
\hline & $\begin{array}{c}\text { Fibra em detergente } \\
\text { ácido indigestível }\end{array}$ & $\begin{array}{c}\text { Fibra em detergente } \\
\text { neutro indigestível }\end{array}$ & Lignina & $\begin{array}{c}\text { Lignina } \\
\text { indigestível }\end{array}$ & Óxido crômico \\
\hline Número de animais & 18 & 18 & 18 & 18 & 18 \\
\hline Média, \% ${ }^{1,2}$ & $93,7 a *$ & $90,9 b * *$ & $74,4 \mathrm{c} * *$ & $90,4 b * *$ & $86,1 \mathrm{~b} * *$ \\
\hline Máxima, \% & 110 & 109 & 83,3 & 116 & 91,9 \\
\hline Mínima, \% & 79,8 & 76,4 & 62,8 & 76,4 & 80,0 \\
\hline Desvio-padrão & 9,64 & 10,1 & 6,81 & 10,1 & 3,04 \\
\hline $\mathrm{CV}^{3}$ & 10,3 & 11,1 & 9,14 & 11,1 & 3,53 \\
\hline
\end{tabular}

${ }^{1}$ Médias na mesma linha seguidas de letras distintas diferem entre si pelo teste Tukey a 5\% de significância.

${ }^{2}$ Probabilidade do teste $\mathrm{t}$ para média $=100$. * $\mathrm{P}<0,01 ; * * \mathrm{P}<0,0001$.

${ }^{3} \mathrm{CV}=$ Coeficiente de variação. 
Em bovinos, Zeoula et al. (2002) e Oliveira Jr. et al.(2004) observaram recuperação fecal completa da fibra em detergente neutro indigestível e estimativas acuradas da digestibilidade da matéria seca por esse indicador, enquanto Barros et al. (2007) relataram recuperação de 120,8\% com digestibilidade aparente da matéria seca superestimada. Também trabalhando com ovinos, Kozlosky et al. (2009) observaram recuperações fecais do indicador fibra em detergente neutro indigestível entre 49,5 e 67,9\%. Os resultados obtidos neste trabalho diferem daqueles observados nas investigações citadas.

Piaggio et al. (1991) relacionaram a grande variação na recuperação fecal da fibra em detergente ácido indigestível e na estimativa da digestibilidade a problemas na filtragem durante as análises e à variação no processo de digestão, devido, por exemplo, a perdas de material pelos poros do saco de náilon. Da mesma maneira, a falta de acurácia das estimativas obtidas com a fibra em detergente neutro indigestível neste estudo pode estar ligada aos mesmos fatores.

Quanto à lignina, estimativas acuradas da digestibilidade aparente da matéria seca foram observadas em bovinos por Oliveira Jr. et al. (2004), enquanto digestibilidades superestimadas foram registradas em ovinos por Correa et al. (2007). Muntifering (1982) também observou baixa recuperação fecal desta fração $(78,4 \%)$ e argumentou que a credibilidade do uso na estimativa da digestibilidade pode ser questionada em casos de evidências da digestão parcial ou da alteração do polímero desta fração durante o processo de trânsito pelo trato gastrointestinal, como relatado em trabalhos com ovinos
(Fahey et al., 1980), em que a digestibilidade aparente média da lignina em vários alimentos volumosos variou de $-76,8 \%$ a $+27,6 \%$. As digestibilidades positivas encontradas por Fahrey et al. naquele estudo podem ser resultado da solubilização parcial dos polímeros de lignina durante o processo de digestão de alguns alimentos. Fatores como a degradação de fenóis polimerizados em forragens imaturas por sistemas enzimáticos presentes em mamíferos e seres anaeróbios (inclusive microrganismos ruminais), a produção de compostos de Maillard em alimentos ricos em proteína (Van Soest, 1994) e a solubilização de parte desta fração pelo detergente ácido utilizado na metodologia de sua determinação (Jung \& Fahey, 1983) podem estar relacionados à baixa recuperação da lignina nas fezes.

Piaggio et al. (1991) avaliaram o uso do resíduo indigestível da lignina na estimativa da digestibilidade aparente da matéria seca em ovinos e, diferentemente do que foi observado neste estudo, obtiveram recuperações fecais iguais a $100 \%$, o que resultou em coeficientes de digestibilidade acurados. A maior recuperação fecal da lignina indigestível em comparação à lignina resultou provavelmente da solubilização da fração da lignina durante o processo de digestão ruminal por 144 horas, a qual seria perdida durante o processo de digestão no trato gastrointestinal total e que acarretaria em menores recuperações do indicador. Esse fato foi comprovado por Berchielli et al. (2000), que relataram que as estimativas da digestibilidade aparente da matéria seca em bovinos obtidas com o uso da fibra em detergente ácido, fibra em detergente neutro e lignina incubados por seis dias no rúmen foram semelhantes à da digestibilidade aparente da matéria seca

Tabela 3 - Acurácia e precisão da estimativa da digestibilidade aparente da matéria seca (DAMS) determinada utilizando-se diversos indicadores em ovinos

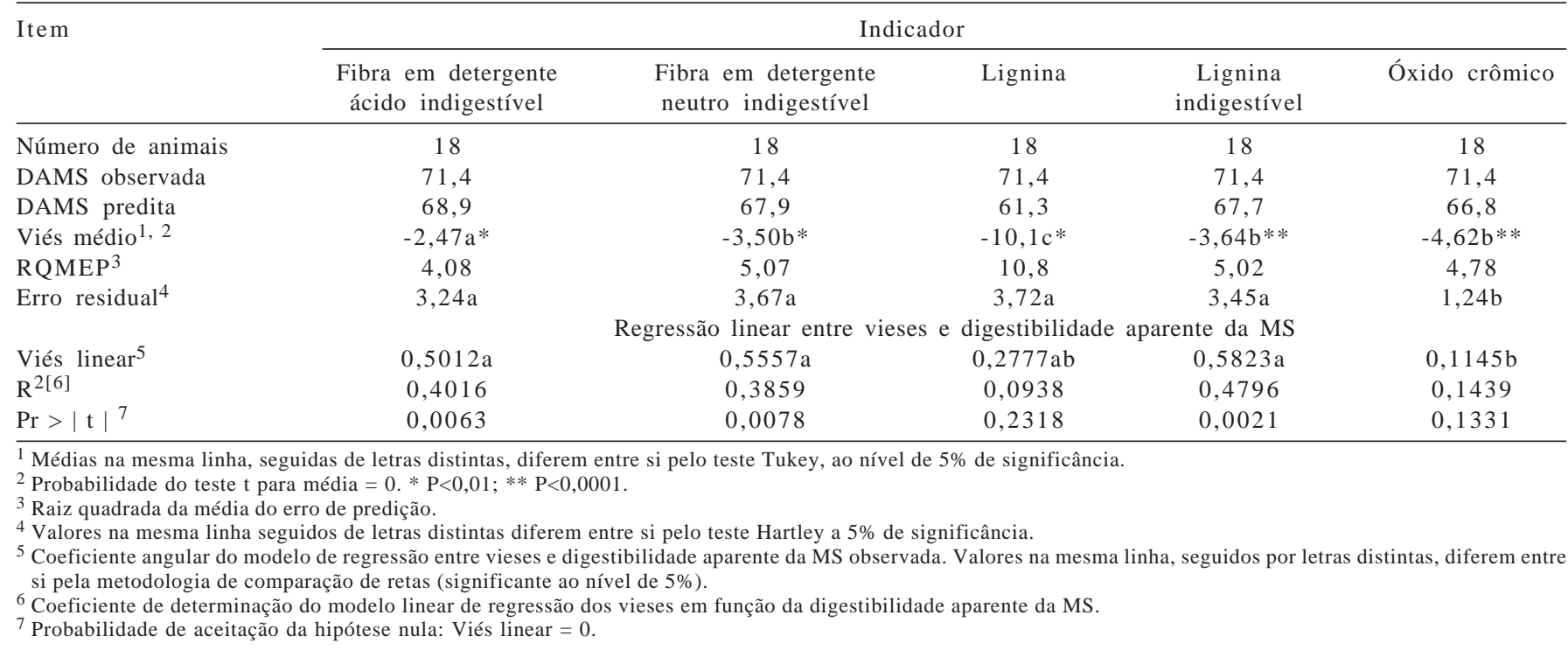


observada com a coleta total de fezes, o que não ocorreu quando os indicadores foram obtidos com a incubação por apenas três dias. Nesta investigação, os indicadores obtidos com incubação ruminal por menor período subestimaram a digestibilidade de todas as frações da dieta. Anteriormente, Lippke et al. (1986) demonstraram que, apenas após 144 horas de incubação, a recuperação da fibra de forragens havia atingido a assíntota. Como a lignina é parte da parede celular vegetal, a recuperação deste indicador é maior quando obtida após longo processo de digestão. As recuperações mais próximas de $100 \%$ para a fibra em detergente ácido indigestível e fibra em detergente neutro indigestível obtidas neste estudo, também podem ter a mesma explicação.

A inacurácia das estimativas de digestibilidade pelo óxido crômico observada na presente investigação tem sido relatada frequentemente (Pereira et al., 1995; Maurício et al., 1996; Barros et al., 2007; Oliveira et al., 2003). Segundo Cuddeford \& Hughes (1990), a excreção fecal diária do óxido crômico não é constante, o que pode ter levado a recuperações, em média, abaixo de $100 \%$ e menores que a de outros indicadores. Outra explicação seria os problemas causados pela forma de administração do metal, uma vez que perdas podem ocorrer por adesão no comedouro ou durante a mastigação, levando a ingestões do indicador inferior à prevista. Por outro lado, Barros et al. (2009) observaram que as estimativas de produção fecal em ovinos realizadas por meio do óxido crômico foram as menos enviesadas que aquelas obtidas por indicadores internos.

Não houve diferença entre os erros residuais (Tabela 3) das estimativas da digestibilidade aparente da matéria seca obtidas pela fibra em detergente ácido indigestível, fibra em detergente neutro indigestível, lignina e lignina indigestível $(\mathrm{P}>0,05)$. No entanto, esses erros foram maiores que aquele observado com o uso do óxido crômico. Desta forma, pode-se sugerir que o óxido crômico foi o indicador mais preciso devido aos menores valores de erro residual, o que concorda com os resultados apresentados por Siqueira (2008) em equinos. É possível ainda que a fibra em detergente ácido indigestível, a fibra em detergente neutro indigestível, a lignina e lignina indigestível tenham apresentado precisões semelhantes.

O viés linear foi maior para fibra em detergente ácido indigestível, fibra em detergente neutro indigestível e lignina indigestível, seguido pela lignina e, por último, pelo óxido crômico (Tabela 3). Além disso, os coeficientes de regressão do viés determinados em função da digestibilidade aparente da matéria seca observada por coleta total de fezes não foram estatisticamente diferentes de zero para lignina e óxido crômico $(\mathrm{P}>0,05)$. Portanto, pode-se afirmar que os erros de predição da digestibilidade aparente da matéria seca originados pelo uso da fibra em detergente ácido indigestível, da fibra em detergente neutro indigestível e da lignina indigestível são influenciados pela digestibilidade da matéria seca da dieta, o que não ocorre para os outros dois indicadores. Os vieses lineares estatisticamente diferentes de zero são positivos e, neste caso, melhoram de acordo com a digestibilidade da matéria seca da dieta (Figura 1). Neste trabalho, o erro de predição das fibras indigestíveis e da lignina indigestível diminui com o aumento da digestibilidade da dieta, comprovando que as estimativas da digestibilidade aparente da matéria seca obtidas por estes indicadores são mais acuradas em dietas com digestibilidades aparentes da matéria seca próximas a $75 \%$. A razão para esse comportamento não é clara. Utilizando-se a lignina como exemplo, Cochran et al. (1988) e Tamminga et al. (1989) afirmaram que é recomendável o uso deste indicador quando sua fração supera $5 \%$ da dieta, sugerindo que erros das estimativas da digestibilidade são mais comuns quando a concentração do indicador na dieta é muito baixa. Considerando essa premissa verdadeira e levando em conta os resultados deste trabalho, o erro de predição seria mais elevado em dietas com maiores coeficientes de digestibilidade, já que estas são geralmente compostas por ingredientes com menor fração indigestível, fato que não aconteceu neste experimento.

A explicação mais plausível para este achado é que, em dietas com mais volumoso, haveria maior probabilidade de desaparecimento do indicador nos ovinos-teste em comparação ao desaparecimento obtido nos sacos incubados no rúmen de bovinos. Isso provavelmente devido ao curto tempo de incubação no rúmen, que foi de 144 horas. Portanto, espera-se que a incubação in situ das amostras por maior período de tempo melhore a robustez desses indicadores internos.

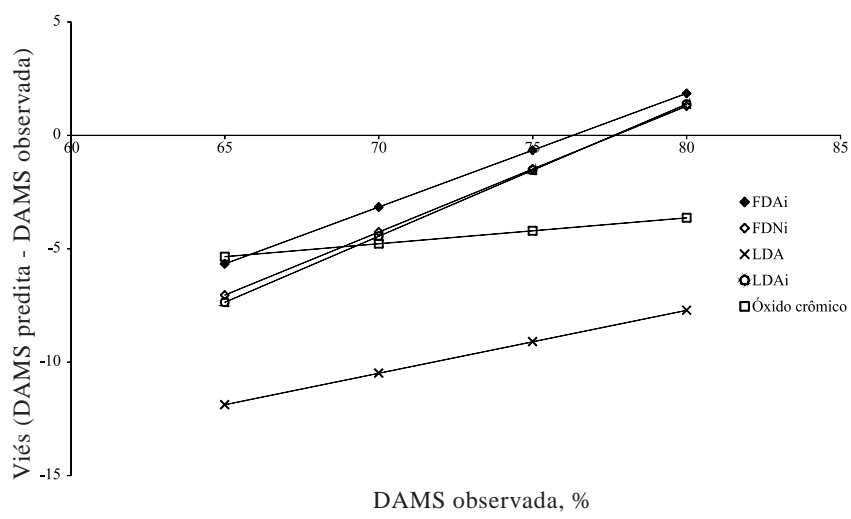

Figura 1 - Viés linear das estimativas da digestibilidade aparente da matéria seca em ovinos obtidas com o emprego de diferentes indicadores. 
Os coeficientes angulares da regressão linear entre o viés e o consumo de matéria seca (Tabela 4) não foram diferentes de zero $(\mathrm{P}>0,05)$ para nenhum dos indicadores avaliados, comprovando que o erro de predição foi independente da variação no nível de ingestão de alimentos. Portanto, todos os indicadores foram robustos na estimativa da digestibilidade aparente da matéria seca quando confrontados por meio desta variável. Cabe destacar que, houve variabilidade suficiente no consumo de MS, que variou de 567,0 a 1.929,0 g/animal/dia.

Entretanto, o mesmo não ocorreu para a robustez dos indicadores avaliados utilizando como variável independente o nível de concentrado na dieta. Os vieses das estimativas da digestibilidade aparente da matéria seca pela fibra em detergente ácido indigestível, fibra em detergente neutro indigestível e lignina indigestível foram moderadamente influenciados pela variação no nível de concentrado das dietas ofertadas aos ovinos $(\mathrm{P}<0,01)$. $\mathrm{O}$ viés diminui com o uso de maiores porcentagens de concentrado na dieta, visto que os coeficientes angulares da regressão linear foram positivos e diferentes de zero $(\mathrm{P}<0,01)$. Esse fato mostra que apenas a lignina e o óxido crômico foram robustos nesta situação (Figura 2).

Esses resultados estão de acordo com os vieses lineares encontrados e já discutidos, uma vez que o erro de predição para fibra em detergente ácido indigestível, fibra em detergente neutro indigestível e lignina indigestível aumentou à medida que os valores de digestibilidade aparente da matéria seca tornaram-se menores. Esse fato pode ser explicado pela provável ligação entre digestibilidade aparente da matéria seca observada e nível de concentrado na dieta, já que espera-se dietas contendo maior nível de concentrado oferecem nutrientes com maior degradabilidade ruminal efetiva e maiores digestibilidades no trato gastrointestinal total como, por exemplo, os carboidratos não-fibrosos.

Os coeficientes angulares da regressão linear entre viés e peso vivo animal não foram diferentes de zero para fibra em detergente ácido indigestível, fibra em detergente neutro indigestível, lignina e lignina indigestível $(\mathrm{P}>0,05)$, logo esses indicadores foram robustos quanto à variação no peso vivo dos animais utilizados no ensaio de digestibilidade (56,5 $\pm 4,6 \mathrm{~kg})$. Ao contrário, o erro das estimativas da digestibilidade aparente da matéria seca pelo óxido crômico foi influenciado $(\mathrm{P}<0,01)$ pelo peso vivo animal, de modo que os valores de digestibilidade aparente da matéria seca foram subestimados em maior grau em ovinos com maior peso vivo (Figura 3). Entretanto, a variabilidade de peso

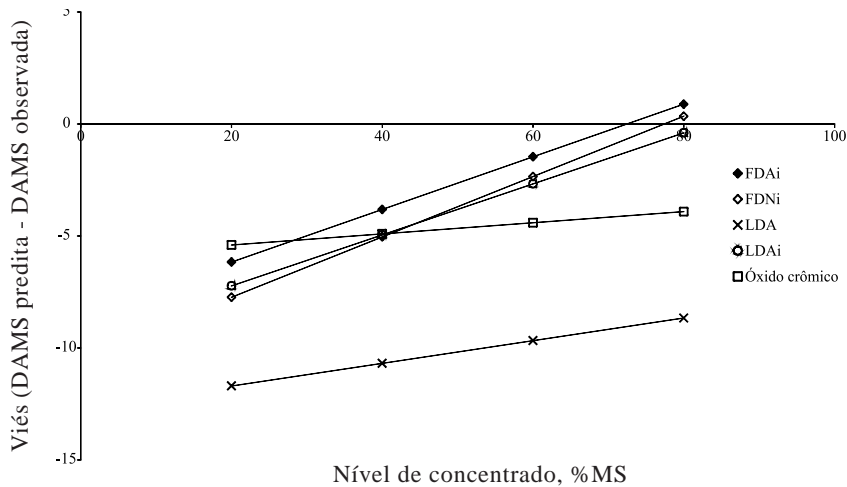

Figura 2 - Regressão linear entre vieses das estimativas da digestibilidade aparente da matéria seca na dieta determinadas em relação ao nível de concentrado da dieta com o uso de indicadores em ovinos.

Tabela 4 - Robustez (coeficiente angular, $\mathrm{R}^{2}$ e probabilidade) das estimativas da digestibilidade aparente da matéria seca determinada utilizando-se diversos indicadores em ovinos

\begin{tabular}{|c|c|c|c|c|c|}
\hline \multirow[t]{2}{*}{ Item } & \multicolumn{5}{|c|}{ Indicador } \\
\hline & $\begin{array}{l}\text { Fibra em detergente } \\
\text { ácido indigestível }\end{array}$ & $\begin{array}{l}\text { Fibra em detergente } \\
\text { neutro indigestível }\end{array}$ & Lignina & $\begin{array}{c}\text { Lignina } \\
\text { indigestível }\end{array}$ & Óxido crômico \\
\hline Coeficiente angular ${ }^{1}$ & 0,0004 & 0,0012 & $-0,0025$ & $-0,0015$ & $-0,0008$ \\
\hline R2 [2] & 0,0015 & 0,0118 & 0,0470 & 0,0206 & 0,0477 \\
\hline $\operatorname{Pr}>|\mathrm{t}| 3$ & 0,8814 & 0,6785 & 0,4032 & 0,5826 & 0,3998 \\
\hline $\mathrm{R} 2[2]$ & 0,5278 & 0,5426 & 0,0744 & 0,4385 & 0,1619 \\
\hline $\operatorname{Pr}>|\mathrm{t}| 3$ & 0,0010 & 0,0007 & 0,2894 & 0,0038 & 0,1093 \\
\hline \multicolumn{6}{|l|}{ Peso vivo } \\
\hline Coeficiente angular ${ }^{1}$ & $-0,1456$ & $-0,1606$ & $-0,0032$ & $-0,2132$ & $-0,1588$ \\
\hline $\mathrm{R} 2$ [2] & 0,0501 & 0,0476 & 0,0000 & 0,0949 & 0,4093 \\
\hline $\operatorname{Pr}>|\mathrm{t}| 3$ & 0,3879 & 0,4002 & 0,9869 & 0,2289 & 0,0057 \\
\hline
\end{tabular}

\footnotetext{
${ }^{1}$ Estimativa do coeficiente angular da equação linear de regressão entre os vieses e a respectiva variável independente. Valores na mesma linha foram comparados pela metodologia de comparação da inclinação de retas e quando seguidos de letras distintas, diferem estatisticamente entre si.

${ }^{2}$ Coeficiente de determinação do modelo de regressão linear entre vieses e a variável independente estudada.

3 Probabilidade de aceitação da hipótese nula: coeficiente angular $=0$.
} 


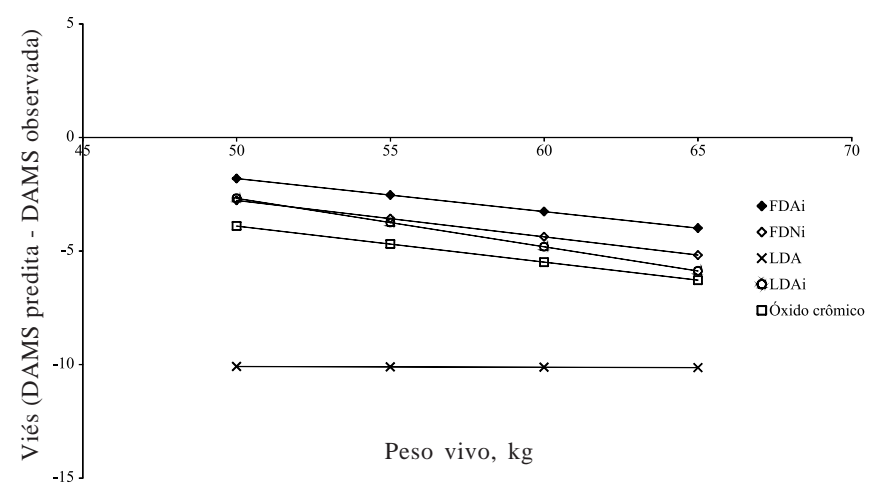

Figura 3 - Regressão linear entre vieses das estimativas da digestibilidade aparente da matéria seca determinadas em relação ao peso vivo com o uso de indicadores em ovinos.

vivo (46,5 a $66,2 \mathrm{~kg}$ ) neste experimento foi modesta para avaliar a robustez dos indicadores.

Variáveis como nível de concentrado na dieta e peso vivo animal podem influenciar mais significantemente as estimativas de digestibilidade por indicadores. Desta forma, é razoável sugerir investigações posteriores para estudo da robustez dos indicadores na presença de variáveis que possam interferir na predição (e em seu erro) da digestibilidade.

No trabalho de Brito et al. (2007), avaliou-se em bovinos, o uso da FDA indigerível e do óxido crômico na estimativa da digestibilidade aparente das frações de dietas variando a concentração de proteína bruta e de energia metabolizável. Os autores não verificaram interação entre indicadores e dieta para a estimativa da digestibilidade aparente da matéria orgânica, sugeriram que, assim como neste estudo, o óxido crômico é robusto quanto à variação de alguns aspectos nutricionais da dieta utilizada.

Ao contrário, Oliveira Jr. et al. (2004) avaliaram o uso de óxido crômico, fibra em detergente neutro indigestível e lignina na estimativa da digestibilidade aparente da matéria orgânica em bovinos e observaram interação entre dieta e indicador de acordo com a fonte de proteína utilizada na ração.

Os resultados desta pesquisa confirmam a grande variabilidade de resultados que o estudo de indicadores da produção fecal é sujeito. Estudos anteriores sugerem que parte desta variação ocorre por erros no processo de isolamento dos indicadores (Barros et al., 2007) e por problemas nas metodologias de análises quando utilizadas frações da parede celular dos alimentos (Jung \& Fahey, 1983).
Entretanto, a acurácia das estimativas da digestibilidade em ruminantes parece ser influenciada mais marcadamente pela composição da dieta oferecida. Os marcadores internos geralmente fazem parte da parede celular dos alimentos. Sua constituição pode diferir entre os tipos de ingredientes (grãos e seus co-produtos, leguminosas, gramíneas ou forragens conservadas) e, no caso dos volumosos, ser afetada pelo estágio de maturação da planta.

Isto é muito bem exemplificado pelas recomendações do uso da lignina. Sua composição varia amplamente de acordo com a região anatômica na planta, o estágio de maturação e os tipos de vegetais. Assim, sua utilização como indicador tem sido sugerida apenas em determinadas dietas (Krysl et al., 1988; Judkins et al., 1990), como aquelas compostas sobretudo por alfafa (Ferret et al., 1999).

Outras evidências colaboram para esta argumentação. Em dietas com alto nível de concentrado para bovinos, a lignina mostrou-se um indicador bastante acurado (Oliveira Jr. et al., 2004), contudo, superestimativas da digestibilidade foram relatadas em ovinos alimentados unicamente com silagem de sorgo (Correa et al., 2007) e baixas recuperações fecais aconteceram em eqüinos cuja dieta foi composta basicamente por feno de gramíneas (Maurício et al., 1996; Oliveira et al., 2003).

Com base nesses resultados, a falta de robustez da fibra em detergente ácido indigestível, fibra em detergente neutro indigestível e lignina indigestível, quando considerado o nível de concentrado, também evidencia que a acurácia das estimativas da digestibilidade aparente da matéria seca por indicadores internos é fortemente influenciada pela composição da dieta oferecida.

\section{Conclusões}

Nas condições deste experimento, as estimativas da digestibilidade da matéria seca da dieta obtidas utilizando-se a FDAi são mais acuradas, enquanto as obtidas com o óxido crômico são mais precisas. Na escolha de um indicador mais adequado, deve-se considerar não apenas sua acurácia (proximidade do valor real) e precisão (variabilidade), mas também o modo e a extensão em que seu viés é influenciado pela variação de fatores relacionados às condições experimentais. Assim, a FDAi parece ser o indicador mais recomendável, especialmente em trabalhos cujo objetivo é gerar dados para criação de tabelas de composição e valor nutricional dos alimentos, enquanto o óxido crômico parece ser o mais indicado para estudos em que o objetivo é comparar fatores dentro de um mesmo experimento. 


\section{Referências}

ASSOCIATION OF OFFICIAL ANALYTICAL CHEMISTS. Official methods of analysis. 10.ed. Washington: AOAC, 1980. 1015p.

BARROS, E.E.L.; FONTES, C.A.A.; DETMANN, E. et al. Avaliação do perfil nictemeral da excreção de indicadores e de óxido crômico em ensaios de digestão com ruminantes. Revista Brasileira de Zootecnia, v.36, n.6, p.2102-2108, 2007 (supl.).

BARROS, E.E.L.; FONTES, C.A.A.; DETMANN, E. et al. Vícios na estimação da excreção fecal utilizando indicadores internos e óxido crômico em ensaios de digestão com ruminantes. Revista Brasileira de Zootecnia, v.38, n.10, p.2015-2020, 2009.

BATEMAN, J. Nutricion animal - Manual de métodos analíticos. México: Herrero Hermanos, 1970. p.405-449.

BERCHIELLI, T.T.; ANDRADE, P.; FURLAN, C.L. Avaliação dos indicadores internos em ensaios de digestibilidade. Revista Brasileira de Zootecnia, v.29, n.3, p.830-833, 2000.

BRITO, R.M.; SAMPAIO, A.A.M.; RESENDE, K.T. et al. Avaliação de indicadores para estimativa das digestibilidades parciais e total de dietas em bovinos. Revista Brasileira de Zootecnia, v.36, n.2, p.445-451, 2007.

CHURCH, D.C. The ruminant animal digestive physiology and nutrition. Englewood Cliffs: O \& Books Inc. 1988, 564p.

COCHRAN, R.C.; VANZANT, E.S.; DELCURTO, T. Evaluation of internal markers isolated by alkaline hydrogen peroxide incubation and acid detergent lignin extraction. Journal of Animal Science, v.66, n.10, p.3245-3251, 1988.

CORREA, R.A.; SILVA, L.D.F.; BETT, V. et al. Consumo e digestibilidade aparente de alguns componentes nutritivos da silagem de sorgo (Sorghum bicolor L. Moench) com ou sem aditivos, em ovinos. Seminários: Ciências Agrárias, v.28, n.1, p.151-158, 2007.

CUDDERFORD, D.; HUGUES, D. A comparison between chromiummordant hay and acid insoluble ash to determine apparent digestibility of a chaffed, molassed hay/straw mixture. Equine Veterinary Journal, v.22, n.2, p.122-125, 1990.

FAHEY, G.C.; McLAREN, G.A.; WILLIAMS, J.E. Lignin digestibility by lambs fed both low quality and high quality roughages. Journal of Animal Science, v.48, n.4, p.941-946, 1980.

FERRET, A.; PLAIXATS, J.; CAJA, G. et al. Using markers to estimate apparent dry matter digestibility, faecal output and dry matter intake in dairy ewes fed Italian ryegrass hay or alfafa hay. Small Ruminant Research, v.33, n.1, p.145-152, 1999.

GRANER, C.A.F. Determinação do crômio pelo método colorimétrico da $\boldsymbol{\sigma}$-difenilcarbazida. 1972. $112 \mathrm{f}$. Dissertação (Mestrado em Zootecnia) - Faculdade de Ciências Médicas e Biológicas/Universidade Estadual Paulista, Botucatu.

JUDKINS, M.B.; KRYSL, L.J.; BARTON, R.K. Estimating diet digestibility: A comparison of 11 techniques across six different diets fed to rams. Journal of Animal Science, v.68, n.4, p.1405-1415, 1990.

JUNG, H.G.; FAHEY, G.C. Nutritional implications of phenolic monomers and lignin: A review. Journal of Animal Science, v.57, n.1, p.206-209, 1983.

KOHN, R.A.; KALSCHEUR, K.F.; HANIGAN, M. Evaluation of models for balancing the protein requirements of dairy cows. Journal of Dairy Science, v.81, n.12, p.3401-3414, 1998.

KOZLOSKI, G.V.; MESQUITA, F.R.; ALVES T.P. et al. Avaliação do uso de frações indigestíveis do alimento como indicadores internos de digestibilidade em ovinos. Revista Brasileira de Zootecnia, v.38, n.9, p.1819-1823, 2009.

KRYSL, L.J.; GALYEAN, M.L.; ESTELL, R.E. et al. Estimating digestibility and faecal output in lambs using internal and external markers. Journal of Agriculture Science, v.111, n.1, p.19-25, 1988.
LIPPKE, H.; ELLIS, W.C.; JACOBS, B.F. Recovery of indigestible fiber from feces of sheep and cattle on forage diets. Journal of Dairy Science, v.69, n.2, p.403-412, 1986.

MAURÍCIO, R.M.; GONÇALVES, L.C.; RESENDE, A.C. et al. Determinação da digestibilidade aparente em eqüídeos através do óxido crômico, da lignina e da coleta total de fezes. Arquivo Brasileiro Medicina Veterinária e Zooetcnia, v.48, n.6, p.703-11, 1996.

MEYER, P.M.; MACHADO, P.F.; COLDEBELLA, A. et al. Fatores não-nutricionais e concentração de nitrogênio uréico no leite de vacas Holandesas. Revista Brasileira de Zootecnia, v.35, n.3, p.1114-1121, 2006a.

MEYER, P.M.; MACHADO, P.F.; COLDEBELLA, A. et al. Validação de modelos de predição de nitrogênio uréico no leite, estimando-se o consumo individual pelo consumo do rebanho. Acta Scientiarum, v.28, n.1, p.73-79, 2006b.

MUNTIFERING, R.B. Evaluation of various lignin assays for determining ruminal digestion of roughages by lambs. Journal of Animal Science, v.55, n.2, p.432-438, 1982.

NATIONAL RESEARCH COUNCIL - NRC. Nutritional requirements of dairy cattle. 6.ed. Washington, D.C.: National Academy Press, 1989. 157p.

OLIVEIRA, C.A.A.; ALMEIDA, F.Q.; VALADARES FILHO, S.C. et al. Estimativa da digestibilidade aparente de nutrientes em dietas para eqüinos, com o uso de óxido crômico e indicadores internos. Revista Brasileira de Zootecnia, v.32, n.6, p.1681-1689, 2003 (supl. 1)

OLIVEIRA JR., R.C.; PIRES, A.V.; FERNANDEZ, J.J.R. et al. Avaliação de indicadores para estimar a digestibilidade dos nutrientes em novilhos Nelore alimentados com dietas contendo alto teor de concentrado e fontes nitrogenadas. Revista Brasileira de Zootecnia, v.33, n.3, p.749-758, 2004.

OTT, R.L. An introduction to statistical methods and data analysis. Wadsworth, 1983. 354p.

OWENS, N.; HANSON, C.F. External and internal markers for appraising site and extent of digestion in ruminants. Journal of Dairy Science, v.75, v.9, p.2605-2617 RE, 1992.

PEREIRA, J.C.; QUEIROZ, A.C.; CARMO, M.B. Avaliação de métodos para determinação da digestibilidade aparente em eqüinos. Revista Brasileira de Zootecnia, v.24, n.3, p.382390, 1995.

PIAGGIO, L.M.; PRATES, E.R.; PIRES, F.F. et al. Avaliação das cinzas insolúveis em ácido, fibra em detergente ácido indigestível e lignina em detergente ácido indigestível como indicadores internos da digestibilidade. Revista Brasileira de Zootecnia, v.20, n.2, p.306-312, 1991.

SAMPAIO, I.B.M. Estatística aplicada à experimentação animal. Belo Horizonte: Fundação de Ensino e Pesquisa em Medicina Veterinária. 1998. 221p.

SIQUEIRA, R.F. Uso da cutina na estimativa da digestibilidade aparente de dietas para eqüinos. 2008. 68f. Dissertação (Mestrado em Medicina Veterinária) - Faculdade de Medicina Veterinária e Zootecnia, Universidade de São Paulo, Pirassununga.

STATISTICAL ANLYSIS SYSTEM - SAS, SAS/STAT User's guide, Release 7.0 ed. Cary, NC: SAS Institute, 1998. 441p.

TAMMINGA, S.; ROBINSON, P.H.; MEJILS, S. et al. Feed components as internal markers in digestion studies with dairy cows. Animal Feed Science and Technology, v.27, n.1, p.49-57, 1989.

VAN SOEST, P.J. Nutritional ecology of the ruminant. 2.ed. Ithaca: Cornell University Press, 1994. 476p.

VAN SOEST, P.J.; ROBERTSON, J.B.; LEWIS, B.A. Methods for dietary fiber, neutral detergent fiber, and nonstarch polysaccharides in relation to animal nutrition. Journal of Dairy Science, v.74, n.10, p.3583-3597, 1991.

ZEOULA, L.M.; PRADO, I.N.; DIAN, P.H.M. et al. Recuperação fecal de indicadores internos avaliados em ruminantes. Revista Brasileira de Zootecnia, v.31, n.5, p.1865-1874, 2002. 